Results Patients with FM reported a mean pain score of 7.0 $(+1.3)$ and mean sleep quality score of $6.5(+1.7)$ on the $0-10$ point scale. Over $95 \%$ of patients selected the descriptors aching, tender and tiring-exhausting. The mean pain score as measured by the VAS of the SF-MPQ was $74.8(+14.2)$ on the $0-100$ point scale. The mean number of tender points was $17.1(+1.5)$ of 18 possible; the mean Tender Point Pain Intensity Score (010 point scale) was $6.1(+1.8)$, while control point mean pain severity was $2.0(+1.9)$.

Conclusion Patients with FM reported a moderate to severe level of pain and sleep disturbance. Pain severity was consistently reported across the three measures of pain, the daily pain diary, the VAS, and the Tender Point Pain Intensity Score. Nearly all patients consistently described their pain as tender, aching and tiring-exhausting. Additional studies need to be completed to characterise further the pain and sleep disturbance prevalent in patients with FM, and to assess and define other symptoms involved in the FM syndrome (see companion abstract by Sesti, et al.).

\section{SAT0139 A CONTROLLED LONG-TERM TREATMENT OF FIBROMYALGIA PATIENTS WITH SERTRALINE}

${ }^{1} \mathrm{P}$ Sarzi-Puttini, ${ }^{2} \mathrm{R}$ Pettorossi, ${ }^{2} \mathrm{~A}$ Baffigi, ${ }^{1} \mathrm{M}$ Cazzola, ${ }^{1} \mathrm{~T}$ Fiorini. ${ }^{2}$ Rheumatology, L. Sacco; ${ }^{2}$ Unit and Laboratory of Clinical Psychology, Catholic University of Sacred Heart, Milano, Italy

\subsection{6/annrheumdis-2001.598}

Background The pathophysiology of Fibromyalgia syndrome (FM) is mostly uncertain and the conventional medication therapy results from empirical research. FM is a common disorder that is estimated to affect $2-4 \%$ of the population. Serotonin reuptake inhibitors are now used in FM due to their interference in the serotonin metabolism.

Objectives To evaluate the relative efficacy and tolerability of Sertraline in the long-term treatment of fibromyalgia patients.

Methods Fifty patients who fulfilled the American College of Rheumatology criteria for the classification of fibromyalgia were entered in a 6-month prospective, controlled trial; all patients were treated with Sertraline (50-100 mg/day). Symptomatic treatment with nonsteroidal anti-inflammatory drugs (NSAIDs) and/or analgesic was allowed at optimal doses that were established on the basis of each patient?s needs. Five control examinations were planned (at baseline, after 15 days at month 1,2,3, and 6). Primary efficacy measures were (1) patient self assessment of pain on a $10 \mathrm{~cm}$ visual analogue scale (VAS), (2) tender point index (TPI) which is the sum of individual tenderness severity at each of the 18 standard ACR tender points and (3) Fibromyalgia Impact Questionnaire (FIQ). Other six secondary clinical efficacy measures were selected: physician and patients' global assessment of the disease, sleep quality assessment using a 100-mm visual analogue scale, Health Assessment Questionnaire (HAQ) the Hamilton rating scale for depression (HRSD) and the Hamilton rating scale for anxiety (HRSA). Tolerability assessment was based on the occurrence of any adverse events.

Results All primary efficacy measures were significantly improved after 1 month of treatment $(p<0.05)$ and maintained a significant improvement throughout the study. No further improvement was however observed after 3 months of treatment. Most of the secondary efficacy measures improved significantly; in particular HRDS and HRSA $(\mathrm{p}<0.01)$ improved after 1 month of treatment. After 6 months of treatment, 23 patients $(45 \%)$ were still on treatment with Sertraline. Most of the withdrawals were due either to inefficacy (12 patients), sideeffects (7 patients) or lost to follow-up (8 patients).

Conclusion Our data confirm the long-term efficacy of sertraline in a discrete percentage of patients with fibromyalgia.

\section{SAT0140 HYPERSOMNOLENCE IN FIBROMYALGIA SYNDROME}

M Rizzi, P Sarzi-Puttini, A Andreoli, B Panni, M Pecis, FG Vassallo, M Carrabba, M Sergi. Servizio Di Fisiopatologia Respiratoria, L. Sacco, Milano, Italy

10.1136/annrheumdis-2001.599

\section{Background}

Objectives To evaluate hypersomnolence in patients affected by fibromyalgia syndrome.

Methods Thirty consecutive patients affected by fibromyalgia syndrome (FMS) (28 F) underwent a general sleep questionnaire, the Epsworth sleepiness scale (ESS), formal polysomnography, and lung function tests.

Results Patients complaining of daytime hypersomnolence had a higher number of tender points $(15 \pm 2$ vs $12 \pm 1$, p $<0.01)$, a greater score of subjective pain $(72 \pm 15$ vs $52 \pm 13, \mathrm{p}=0.05)$ and more fatigue $(\mathrm{p}=0.04)$, about twice as many arousals per hour and a lower sleep efficiency than patients who did not report this symptom. TLco was more impaired and the occurrence of $\mathrm{PB}$ higher.

FMS patients who referred daytime somnolence slept significantly less efficiently than the FMS with no day time somnolence $(\mathrm{p}<0.05)$, had a lower proportion of stage 3 sleep $(5 \pm$ $2 \%$ vs $12 \pm 3 \% ; \mathrm{p}<0.001)$, stage $4(1 \pm 0.5 \%$ vs $4 \pm 1 \%$; $<0.001$ ), and twice as many arousals per hour of sleep ( $\mathrm{p}<$ $0.01)$. The respiratory pattern of FMS patients with hypersomnolence showed a higher occurrence of periodic breathing ( $p=$ 0.02). The short length of apneas and hypopneas did not affect the apnea/hypopnea index $(5.1 \pm 3$ vs $7 \pm 4 ; \mathrm{p}=\mathrm{ns})$, but FMS patients with daytime hypersomnolence had a greater number of desaturations per hour of sleep $(11 \pm 6$ vs $6 \pm 5$; p < 0.05). Pulmonary volumes did not differ between the two groups.

Conclusion The occurrence of daytime hypersomnolence in FMS patients, is linked to a greater severity of fibromyalgia symptoms and to a more severe polisomnographic alterations.

\section{SAT0141 THE EFFECTS OF MIRTAZAPINE IN THE TREATMENT OF FIBROMYALGIA SYNDROME}

W Samborski, M Lezañska-Szpera, JK Rybakowski. Rheumatology, K. Marcinkowski University Medical School, Poznan, Poland

\subsection{6/annrheumdis-2001.600}

Background Some previous study has documented the efficacy of 5-HT3 receptors antagonists in the treatment of fibromyalgia. Objectives The mirtazapine (Remeron), a new generation antidepressive agent, characterised by blocking of 5-HT2 and 5-HT3 receptors and stimulation of 5HT-1 and noradrenergic receptors was used in the treatment of patients with Fibromyalgia syndrome (FS).

Methods Twenty patients (18 female, 2 male), age range 20-64 years, mean 43,58, fulfilling the 1990 ACR criteria for fibromyalgia, entered 6 weeks open study and were given $30 \mathrm{mg}$ mirtazapine per day. Before the administration of the first dose, during the study and at the final visite, the following parameters were measured using the visual analogue scale 0-10 (VAS): pain, 